\title{
Interactive Lab to Learn Radio Astronomy, Microwave \& Antenna Engineering at the Technical University of Cartagena (Spain)
}

\author{
doi:10.3991/ijoe.v7i1.1523 \\ José Luis Gómez-Tornero, David Cañete-Rebenaque, \\ Fernando Daniel Quesada-Pereira and Alejandro Álvarez-Melcón \\ Technical University of Cartagena, Cartagena, Spain
}

\begin{abstract}
An initiative carried out at the Technical University of Cartagena (UPCT, Spain) to encourage students and promote the interest for Scientific and Engineering Culture between society is presented in this contribution. For this purpose, a long-term project based on the set-up of an interactive laboratory surrounding a small Radio Telescope (SRT) system has been carried out. The main novelty is that this project is entirely being developed by students of last courses of our Telecommunication Engineering Faculty, under the supervision of four lecturers. This lab offers the possibility to remotely control the SRT, and it provides a set of multimedia web-based applications to produce a novel, practical, multidisciplinary virtual laboratory to improve the learning and teaching processes in related sciences and technologies.
\end{abstract}

Index Terms-Electrical engineering education; Electromagnetic engineering education; Systems engineering education; Radio Astronomy; Remote and Virtual Laboratories.

\section{INTRODUCTION}

As we are immersed in the "Bologna process" to reach the EEES (European Space for Higher Education) [1], academic and government regulators request for innovate experiences to improve the learning process, highlighting the necessity to develop of more practical, less theoretical, teamwork, interdisciplinary competencies. Very worrying is the reality detected in the last decade which shows that young people around Europe are losing their interest in Science and Engineering culture (see, for instance the objectives and efforts made in Spain by FECYT [2]). Being aware of these facts and feeling responsible as part of a public Spanish University, some lecturers of the Telecommunication Engineering Faculty at the Technical University of Cartagena (UPCT, Spain) decided to undergo the experience of involving our last course students in the development of a Small Radio Telescope (SRT) and set-up of an associated laboratory where to boost practical and multidisciplinary competencies in the subjects of Radio Astronomy, Microwave and Antenna Engineering.

These lecturers coordinate some telecommunications related syllabus like Electromagnetism [3,4], Antenna Engineering [5,6] Microwave Engineering [7-8], or Radio Communication Systems [10]. We thought that Radio Astronomy [11-14], and particularly Amateur Radio Astronomy [15-17] is a very exciting application of

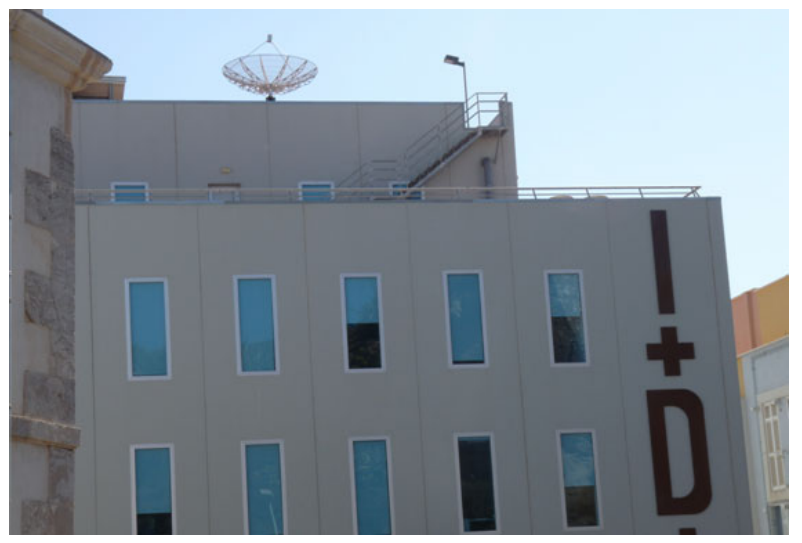

Figure 1. SRT parabolic antenna located at UPCT campus

Antennas and Microwave Engineering that might motivate students to put effort in these courses [18]. Moreover we thought that involving the students in the setting-up, operation, maintenance and enhancement of a SRT system could be a good idea to have a permanent practical laboratory where they could feel free to improve their knowledge and skills related with these technologies. Besides, this laboratory can serve as a tool to attract future students to our Faculty, and it is also very useful to disseminate Radio Astronomy between non-specialized individuals, local amateur astronomers [19,20], and society in general.

A picture of the actual SRT antenna is shown in Fig.1; it is a 3-metre home-made parabolic dish antenna which has been placed on the top floor of a building at the UPCT campus. This antenna is the most symbolic and eyecatching part of this laboratory, which extends to many more aspects. The scheme of all the elements that arrange the entire laboratory are sketched in Fig.2. A horn antenna and a Low Noise Block (LNB) are positioned at the dish focus. The incoming Radio Frequency (RF) signals from the outer space are focused by the reflector dish and received by the aforementioned LNB. High-quality (low loss) coaxial cable is used to transmit the RF signal to the physical laboratory room, where the RF receivers convert the RF analog signal into a low-frequency digital signal, which is acquired and processed by a computer. This computer also remotely controls the antenna engines, and a webcam is used to visually monitor the antenna from the lab, as illustrated in Fig.2. 


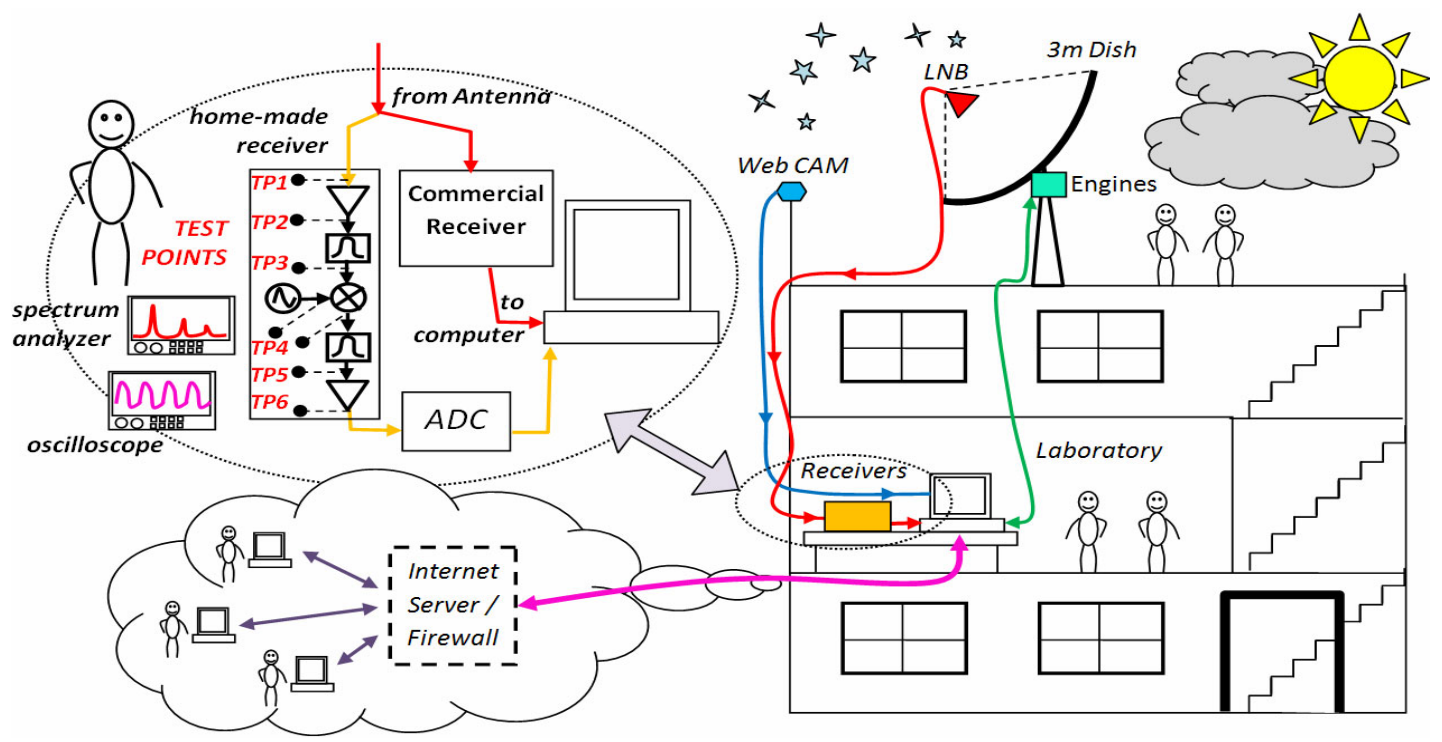

Figure 2. Scheme of the Radio Astronomy \& Microwave and Antenna Engineering Laboratory

A commercial digital RF receiver [21] and a homemade analog RF receiver are used in parallel, as shown in Fig.2. The digital commercial receiver provides better performance than the analog home-made one. However, the domestic receiver is of key importance in this lab for two reasons. First, it has been entirely designed, manufactured, tested and developed by the students and lecturers of the UPCT. As it will be explained later, this is one of the main objectives of this project. The second reason to have a home-made receiver is that it has been designed as a microwave receiver trainer to learn fundamental practical concepts about analog RF signal reception and processing. This receiver has several test-points (TPs shown in Fig.2) which can be directly accessed by the students using RF probes to measure the RF signals (using spectrum analyzers and/or oscilloscopes), to visually understand the analog RF signal processing. The process and methodology used to develop this custom-made RF receiver is explained in Section III-A of this paper, and a scheme of the RF hardware subsystems associated to this SRT is shown in Fig.3.

It must be reminded that a Radio Telescope can be used at any time (daylight hours or night hours) and even in a cloudy day, due to the nature of radio waves and the Earth's atmosphere, in contrast to optics Astronomy, limited to clear night's observations [11]. This is an important aspect when considering a teaching facility, which should be operated at office hours and without strongly depending on weather conditions.

Apart from the hardware, the lab includes the necessary software to acquire, store and process the signal received by the SRT, and also to calibrate the receiver and to control the positioning of the antenna. Besides, a local server holds many technical documents, related information and interactive applications created for this laboratory. These technical documents include all the reports describing the development of each part of this SRT during the past six years (since 2004). Also, interactive multimedia webbased applications have been created to explain how the SRT works, using this SRT application to explain Radio Astronomy, Antenna and Microwave Engineering fundamentals. Some of these applications will be described in
Section III-B of this paper. Finally, the remote access to this laboratory via Internet (both to control the actual SRT and to use the web-based documents and applications) has been considered as shown in Fig.2 (not implemented yet).

The main novelty of this activity is that the entire SRT system (see scheme in Fig.3) has been entirely developed, manufactured, tested and set-up by the students, using the facilities available in our modest laboratories. Also, all the aforementioned web-based documents and interactive applications which create a virtual laboratory, have been mostly developed by UPCT students and lecturers. To our knowledge, this is the first proposal in Spain to promote Radio Astronomy with these particular characteristics. Other public Spanish Universities proposals, such as the ones from the University of Valencia [22] or the University of Cantabria [23] have also made use of a SRT to introduce their students of Physics and Astronomy to this fascinating world. However, in these cases, the entire SRT was designed, manufactured and sold by external Engineering companies [21,24-26]. Another well-known example is the Spanish-NASA project known as PARTNeR [27] started in 2004, and which involves the use of the $34 \mathrm{~m}$ diameter NASA Radio Telescope at Robledo de Chavela (Madrid, Spain) to disseminate Radio Astronomy among high-school and University students [28]. Like other Spanish professional Astronomy institutions such as IAA [29] or IAC [30], these initiatives make use of professional and large Radio Telescopes with the aim to make public their facilities and divulgate Radio Astronomy to

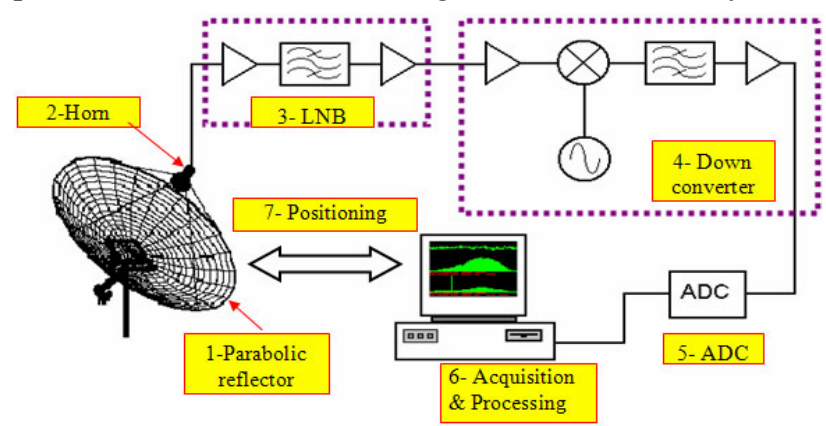

Figure 3. Scheme of the SRT RF system and subsystems 
society. On the contrary, the initiative proposed and carried out at the UPCT has an academic origin, with the main objective to stimulate the potential and improve the learning process of our graduate and postgraduate students in the fields of Electromagnetism, Antenna and Microwave Engineering, and Signal Processing. In the international picture, similar university projects can be found at MIT Haystack Observatory (Boston, MA) [31], Cardiff University (UK) [32], or Saint Mary's University (Canada) [33]. Nevertheless, a secondary objective and interesting consequence is the application of this project to share this amateur SRT between high-school students, local Astronomy associations and society in general, trying to attract new students to our faculties and improve the interest of young people for Science and Engineering. A similar task in an international level can be attributed to the SETI (Search for Extra Terrestrial Intelligence) team [34], in his aim to let individuals collaborate in this search, with projects as the SETI@home [35] or the development of amateur SRTs for SETI Argus Project [36-37].

In this paper, the particular objectives of the SRT lab project undergone at the UPCT are described in Section II. Section III illustrates the modules of this lab and the methodology used to improve the learning process of the aforementioned undergraduate and postgraduate courses. Section IV addresses the response of the students and the results obtained by this initiative, and finally Section IV depicts the main future lines envisaged as a consequence of this project.

\section{OBJECTIVES AND BENEFITS}

The main objectives of this initiative, and the associated benefits for the students, can be summarized as follows:

1- Development of a small radio telescope (SRT) capable of detecting the L-band emissions of atomic hydrogen $(1.42 \mathrm{GHz})$. This frequency was chosen since the hydrogen line emissions from our Galaxy are quite abundant and relatively strong [11]. Moreover, this microwave range provides understanding of high-frequency related phenomena studied in Antenna [5-6] and Microwave [710] Engineering without overcoming the $6 \mathrm{GHz}$ band, in which the manufacturing and testing of circuits and antennas becomes much more expensive and difficult. Therefore, the microwave receivers working at this frequency are relatively easier and cheaper to design and manufacture, if compared with higher frequencies or more sensitive receivers which are not affordable for modest laboratories.

2- The SRT RF system (see Fig.3) must be entirely designed, manufactured, tested, set-up and maintained by our students. In this way, the students face a complex project, in which practical, interdisciplinary, teamwork competences must be developed with a concrete target. In this way, we try to make the students realize of their actual developed abilities as future engineers (particularly in the fields of Antenna, Microwave and Electronic Engineering). It has been found that many students have the feeling of having developed too theoretical, poor practical skills in our Engineer faculties, feeling unprepared for real practical works $[1,2]$. Even if the lectures do not believe that this feeling corresponds to reality, it is good to make the students realize from an early stage about their actual abilities to face real, practical, complex, interesting engineering projects, so they feel more motivated and confident.

3- The SRT system involves different theoretical concepts which the students are supposed to have gained during their graduate and undergraduate courses (mechanics, physics, astronomy, electronics, electromagnetism, microwave circuits, antennas, signal processing, instrumentation...). In this way, we make the students develop interdisciplinary skills, gathering the knowledge of all these courses together to face this work. We believe that this is a more realistic and practical position for them to face the real world, opposed to the academic perspective of "unconnected courses" so often addressed by graduate students.

4- Apart from being multidisciplinary, we also look for development of teamwork competences, needed for practical big projects which cannot be faced by a single person.

5- Particularly, it is desired to develop a home-made RF analog receiver trainer (see scheme in Figs.2 and 3) with the main purpose to serve as a didactical tool to assist in the learning/teaching process of analog high-frequency signal reception and processing [3-10]. This custom-made receiver must be modular with easy and direct access to different test points, in order to visually illustrate the basic steps of microwave signal reception, amplification, filtering, demodulation and acquisition.

6- Once the initial SRT has been set-up and installed at UPCT, it is intended to be a constant tool for teaching and upgrading. The basic system provides an excellent laboratory to make permanent improvements and develop future projects in any of the associate disciplines and technologies. The idea is that the students of UPCT must feel fry to conceive and propose new project which might upgrade the performance of the SRT, working out their creativity and research abilities.

7- A local server must hold online multimedia documents, reports and interactive applications, related to this SRT, so that a virtual laboratory can be envisaged.

8- Secure real-time remote control of the actual SRT, and internet access to the virtual lab, is considered as an interesting aspect to disseminate this initiative among interested students, lecturers and researchers.

9- A deeper and more general objective is to use this SRT to attract young people and increase their interest in Sciences and Technology [1]. Particularly, the SRT is intended to help in the recruitment of new students to our Engineering Faculties [2].

10- Radio Astronomy [11-14] is not as spread and known in society as its optical counterpart, probably due to the complexity associated to microwave circuits and antennas [11]. The SRT has also the social objective of introducing students and amateur astronomers [19, 20] to Radio Astronomy and linked technologies.

\section{LAB MODULES AND METHODOLOGY}

As described in the introduction of this paper, and illustrated in Fig.2, this laboratory can be decomposed in the two following basic modules:

a) SRT HARDWARE / SOFTWARE

b) WEB-BASED DOCUMENTS / APPLICATIONS 
In this section, these two modules are described together with the particular methodology used to assist in the learning process of our students.

\section{A. SRT Hardware and Software}

The most visible part of the SRT project is the 3-metre parabolic antenna, as can be seen in Fig. 1. The antenna acts as a reflector, focusing the incoming weak radio frequency signals received to the dish focus, where the Low Noise Block (LNB) is located (see scheme in Fig. 2). There, the signal is amplified and filtered to remove undesired interferences and to provide the required power level to be transmitted though a high quality low-loss coaxial cable to the laboratory room, located two levels below the roof, as seen in Figs.1-2.

From the laboratory it is possible to control the antenna and to analyze the obtained data. On the one hand, a computer is able to remotely control the antenna engines, and to control the movement of the antenna, using the system provided by RF Ham Design company [26]. The engines control requires the following elements to completely operate the movement of the antenna:

- Two engines (azimuth and elevation) located on the basis of the antenna and coupled to the parabolic dish. In this way the engines can tilt the antenna in order to observe almost any desired point of the visible celestial sphere.

- The engines are connected to a Azimuth \& Elevation Rotor Controller (located in the laboratory, see Figs.2 and 4). This device controls the movement of the engines, supplying the necessary electric power and providing an interface between the computer and the engines.

- Drivers and specific software to operate the digital controller with the computer. The software used is the Orbitron, a cardware Satellite Tracking System used by many radio amateurs, weather professionals, satellite communication users, astronomers and UFO hobbyist [38]. It allows the introduction of coordinates or movement equations to point at or to follow any celestial object in the firmament.

On the other hand, the radio frequency signal transmitted from the antenna must be acquired and then processed by a computer. To assist in the learning /teaching process of analog high frequency circuits, a commercial digital RF receiver and a home-made analog RF receiver are used in parallel (see Fig. 2). The commercial receiver is the Spectra Cyber $1420 \mathrm{MHz}$ Hydrogen Line Spectrometer developed by Radio Astronomy Supplies (RAS, [21]), which allows the user to manage reliable astronomical data and guarantees the robust and immediate operation of the complete system.

The domestic receiver is probably the most important part in this lab because it is composed of several subsystems which have been entirely designed, manufactured, tested and developed by the students and lecturers of UPCT, being this one of the key objectives of this project. Besides, this home-made receiver has been designed as a microwave receiver trainer to learn practical concepts about analog RF signal reception and processing. This receiver is composed of several microwave subsystems carrying out specific functions (filtering, amplifying, mixing..., see scheme in Fig.3) required for the appropriate reception of the incoming $1420 \mathrm{MHz}$ RF signal. The whole domestic receiver subsystem has been manufactured in printed-circuit microstrip technology (see Fig.6), locating on the same substrate all the aforementioned microwave circuits and including test points (TPs shown in Fig. 2 and Fig. 6).
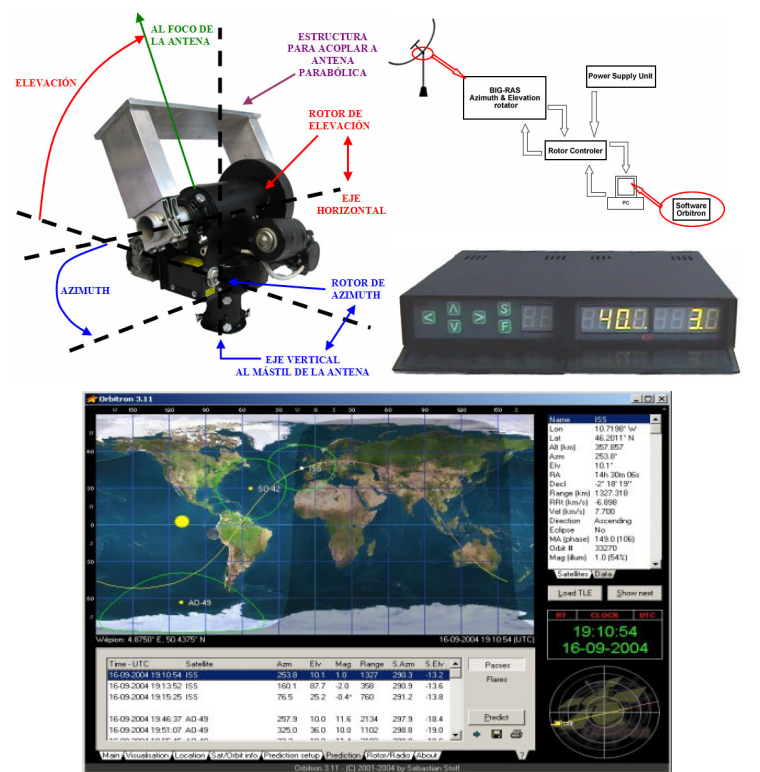

Figure 4. SRT positioning subsystem: Engines (upper left) and digital controller (upper right) [26] and Orbitron tracking software (down) [38]
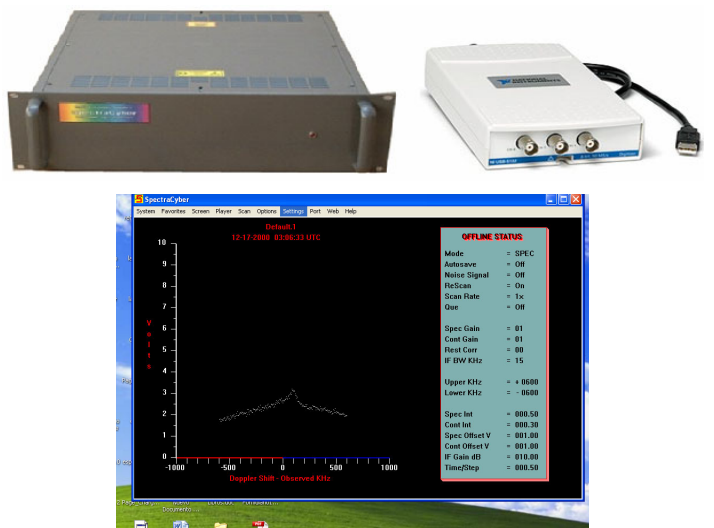

Figure 5. SpectraCyber digital receiver provided by RAS [21] (upper left) USB digitizer NI USB-5133 (upper right) and SpectraCyber software to analyze the hydrogen line spectrum.
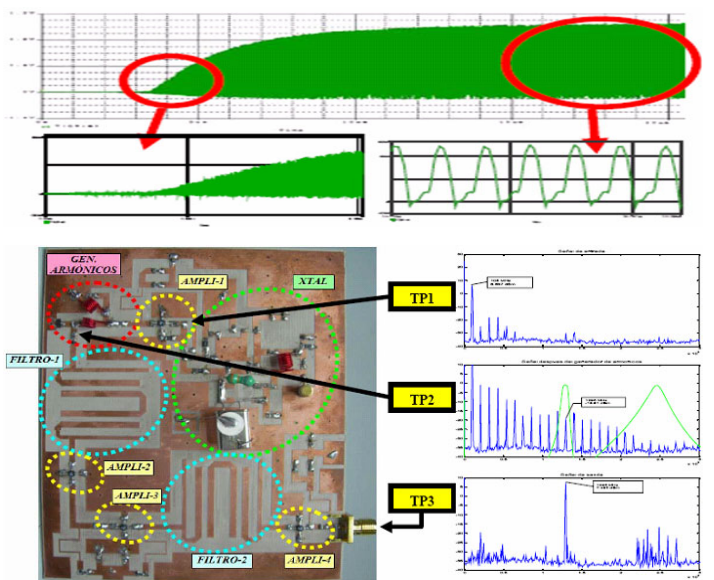

Figure 6. SRT home-made receiver, showing different test points and $\mathrm{RF}$ signals measured with an oscilloscope (up) and a spectrum analyzer (right) [45]. 
The objective is that the test points are directly accessed by the students using RF probes and measurement instrumentation (spectrum analyzers and RF oscilloscopes) to measure the signals at different stages of the receiving process. In this way, a visual and practical understanding of the analog RF signal processing is provided to our students. It should be pointed out that these circuits, although connected and dependent on each other, have and individual particular function, which corresponds to a specific type of signal processing. Moreover, these subsystems cover most of the type of circuits used in analog microwave systems [10], so that the concepts involving the design and the development of such subsystems can be easily generalized to many other applications concerning telecommunication engineering and microwave applications $[7,8]$.

Each subsystem has been developed by a student of a group of students during their MSc. project. Fig.7 shows the common steps involved in the work performed by the students to achieve this goal:

1. Theoretical study of the particular system, using recommended textbooks [3-10] or references developed by the supervising lectures [39].

2. Computer aided design (CAD) and simulations using commercial software, such as Ansoft High-Frequency Structure Simulator HFSS [40] for linear electromagnetic three dimensional simulations, Agilent Advance Design System ADS [41] for linear electromagnetic planar circuit simulations, Applied Wave Research Microwave Office-MWO [42,43] for microwave circuit linear and non-linear frequency analysis, and Orcad PSPICE [44] for microwave circuit non-linear transient time-domain analysis. Depending on the type of subsystem, the student might have to use one of these packages (or a combination of them), so that the her or she must learn the main differences, similarities and applications of each one of these commercial microwave CAD tools.

3. Physical design of prototypes using the more convenient technology. Particularly, planar microstrip PCB (Printed Circuit Board) technology [9] has been used for the domestic receiver (LNAs, RF filters, local oscillators, mixers, IF filters), while waveguides are used for the LNB filters and horn.

4. Fabrication of the prototypes using UPCT manufacturing facilities. The students gain at this stage a novel practical perspective about manufacturing processes (possibilities, limitations, applications), which usually have not been gained in previous courses.

5. Testing of the circuits, using the RF instrumentation available in the laboratories. Again, depending of the particular subsystem and technology, different types of measurements and instruments might be used, such as DC voltage supplies, RF generators, spectrum analyzers, network analyzers, RF probes and oscilloscopes. This part is also very interesting for the students, since they deal with real instrumentation which is not used in most of the theoretical courses.

6. After comparing the results of their experiments with the theoretical design and CAD simulations, it is common that the student must readjust or even redesign the circuits to improve the performance of

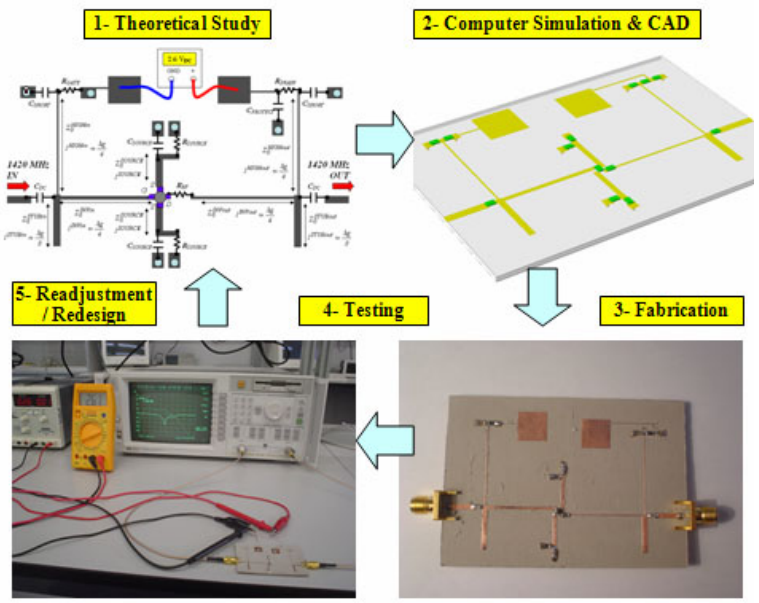

Figure 7. Development of a SRT microstrip low noise amplifier.

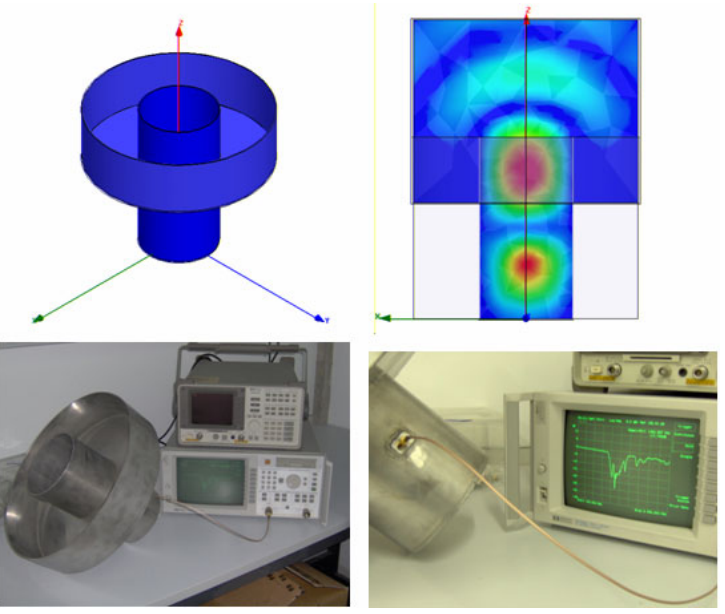

Figure 8. Development of the SRT horn feeding the parabolic reflector

the current designs. In this stage, the students learn the difference between the world of CAD model and the real world, understanding also the importance of using accurate and efficient electromagnetic /electronic simulation tools.

Fig.7 schematically show an example of this methodology applied to the design of a low noise amplifier (LNA). Other subsystems of the SRT (mixer, local oscillator, RF filters, horn, parabolic reflector and positioning subsystem, see Fig.3) have been developed using similar approaches. As another illustrative example, Fig.8 illustrates the development of the SRT horn using an aluminum circular waveguide. Moreover, it must be said that in these six years of work, several improved versions of each subsystem have been designed, so that the students collected the work done in previous years by preceding colleagues, and they worked hard to progress to enhance the performance of the whole SRT. We believe that this method is very instructive and encouraging for students, since they feel that they are part of a big and complex project in which many people are involved, developing multidisciplinary and teamwork skills.

\section{B. Web-based Documents and Applications}

One of the main objectives of the SRT project is introducing Telecommunication/Electrical Engineering students and amateur astronomers to Radio Astronomy and related technology, in order to promote the interest in 
science and engineering studies by showing a practical, complex, and exciting application of many concepts learned during the University degree courses.

To complete this task, several initiatives have been executed, and others are prepared to be completed in the near future. A local server holds online multimedia documents, technical reports and interactive applications, all of them linked to the SRT project. In addition, on-line access to the virtual lab, database containing astronomical data from observed RF sources, and the secure real-time remote control of the actual SRT is being considered. The software used to control the SRT and to process the acquired data run in a common Windows environment within a user friendly interface. Therefore, one of the most exciting programmed features includes the ability to run the program remotely over a local LAN or the Internet. Firstly, this possibility will only be accessible to lecturers in charge of the project. For instance, it will allow logging on the virtual lab via a home computer, a laptop or even a cell phone. Remote users will access the SRT control and acquisition software to observe at a specific location, and to process the purchased astronomical data.

Finally, a web-page has been created to hold and share updated information of this project [46], including general information about Radio Astronomy and Microwave and Antenna Engineering. Particularly, this web page holds all the technical reports derived from the students' MSc projects, including animated presentations and some interactive applets, which might be useful for other people interested in amateur Radio Astronomy and practical Microwave/Antenna Engineering. Fig. 9 shows the current introduction section of the aforementioned SRT web page, where Radio Astronomy basics and the motivation and objectives of this project are explained. Also, it can be found a detailed explanation of the SRT system and subsystems, a full description of the chronological development of the project, data on the localization at the UPCT campus and R\&D building [47], financial support, people that have worked in this project, and other interesting related information. Of course, all these records are open and available to all Internet user. An English version of the web page is being prepared to target to an international level. We encourage the reader interested in the SRT project to visit this web page, and to contact the associated lecturers for any suggestion or collaboration.

From our point of view, two sections of the web page have a particular interest. Selecting the tab "Technical reports" one can access the work done in each particular subproject executed in the development of the SRT, as explained in Section III-B. Reports in pdf format and summary presentations, give comprehensive information for each different subsystem that compose the SRT. As commented, this resources can be downloaded for free, and they represent an invaluable source of useful information for other lecturers and amateur radio astronomer which might be interested in this initiative. The technical reports are divided attending to the subsystems, and they include the design process, the resources needed, manufacturing and measurements issues, and the conclusions derived from each subproject. Fig.10 shows the aspect of this part of the SRT web page.

Another remarkable section is dedicated to on-line interactive applications. Educational applets have been developed by lecturers and students to assist in the visual understanding of the operation of high frequency circuits

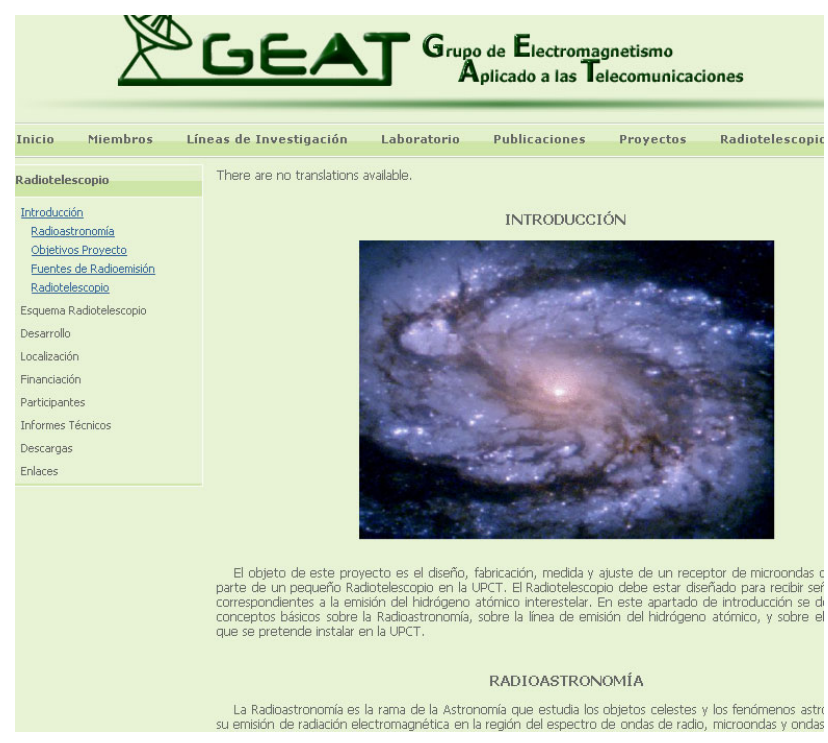

Figure 9. UPCT SRT-project web page [46].

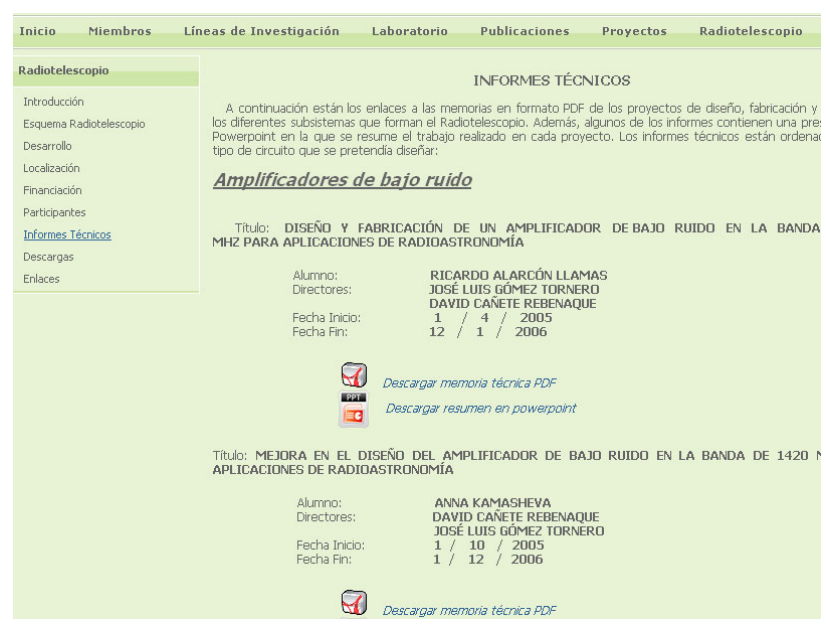

Figure 10. Example of technical reports section [46].

and transmission lines. Under the generic name of M.C.S.I. (MiCrowave Scene Investigation) [48] several web-based applets are gathered. Different high frequency circuits, transmission lines and common fabrication technologies used in the SRT are treated. The application shows in an interactive way design guidelines, layouts, typical frequency responses for all these circuits. Also, animations of the electromagnetic fields and currents flowing in these circuits are used to better visualize and understand the operation of such microwave devices.

Fig. 11 shows a picture of MCSI web page. The user may select different microwave/antenna technologies (microstrip, waveguide...), and study several essential circuits and subsystems (transmission lines, antennas, amplifiers, oscillators, mixers, filters...). For each selection, the function of the circuit, its applications, operating principles, design guidelines and expected frequency response are illustrated, Particularly, the user can observe the fields/currents and the response of the circuit when it is correctly designed, and also when the circuit has not been properly designed. In this way, a more comprehensive, interactive and constructive learning process is achieved. For instance, Fig 12 shows a typical branch-line $90^{\circ}$ hybrid circuit [7] in microstrip technology. This fourport circuit has several operation possibilities to combine 


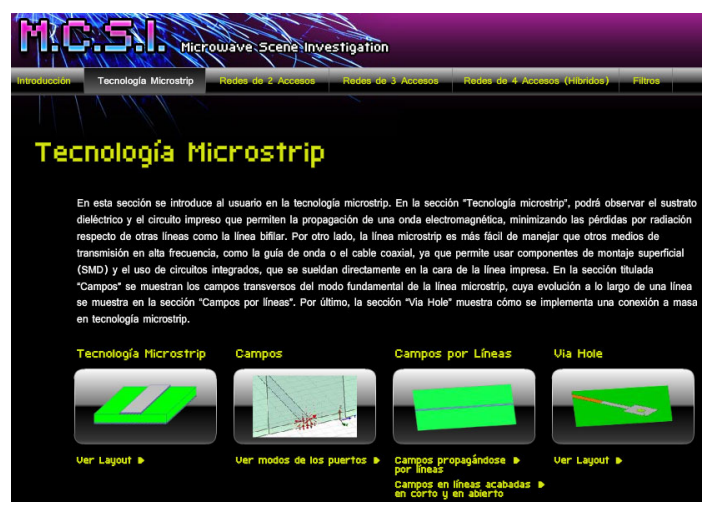

Figure 11. Interactive educational application M.C.S.I.[48]
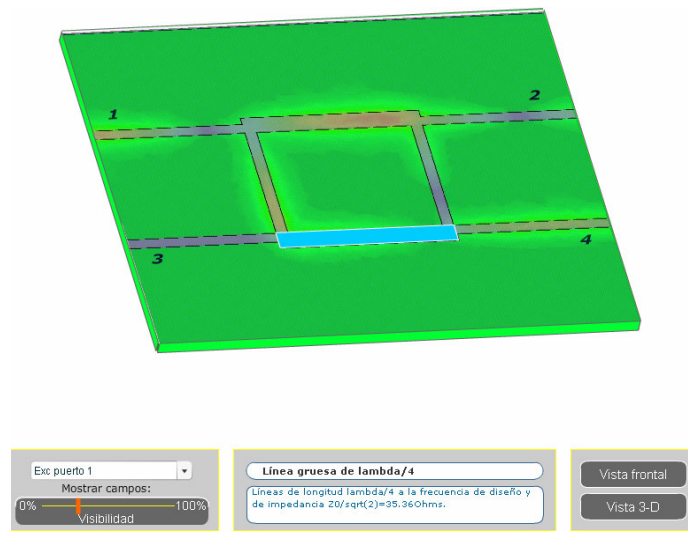

Figure 12. M.C.S.I. example: Brach-Line operation [48]

or split microwave signals. Fig. 12 shows the electromagnetic fields evolution when the circuit is fed in Port 1 , and the signal is split into Port 2 and 4 with different phase, while Port 3 is isolated. In addition, Fig. 12 shows that one transmission line of the hybrid is selected highlighted and a textbox explains its main design parameters (line length and characteristic impedance). Other instructive possibilities available for this circuit are: change the excitation port (or even to feed two ports at the same time with different phase shifts), change the view mode (perspective, show electric field or current density), and represent the scattering parameters. And all these features can be repeated in the two aforementioned scenarios: correct design / wrong design.

\section{RESUlts AmONG THE STUDENTS}

To evaluate the degree of success of this initiative, with respect to some of the objectives described in Section II, several questions were addressed to the students (a total of 41 ), once they had finalized their project for the SRT. The questions are summarized below:

1- Do you think working in this project has made you improve your practical abilities?

(Not at all, Not sure, Sure)

2- Do you think this project has been relevant in your formation as a future Engineer? (Not at all, Not sure, Sure)

3- Do you think that this project has been relevant to better understand the associated disciplines that you studied in previous courses (microwaves and antennas)?

(Not at all, Not sure, Sure)

4- Do you think that this project has improved your teamwork skills?

(Not at all, Not sure, Sure)
5- Do you think that this project has improved your motivation and interest about the degree you studied?

(Not at all, Not sure, Sure)

6- Do you think that this type of projects could substitute the associated theoretical courses? (Not at all, Not sure, Sure)

All the students responded to questions 1-5 with the "Sure" answer, showing an excellent degree of success among the students with respect to objectives 2-4 of Section II. Regarding question 6 , it is interesting to note that $45 \%$ of the students answered "Not at all", a $26 \%$ answered "Not sure" and the remaining 29\% answered "Sure". Obviously, this project is not intended to replace the theoretical courses, which in opinion of this lecturers are indispensable for the students in order to face the more practical projects proposed in this SRT initiative (as 45\% of the students addressed).

From the lecturers' point of view, it is being a satisfying experience (despite the big effort and time of dedication needed to supervise these projects), since the students showed high degree of interest and satisfaction, presenting own judgement and clever ideas, and yielding fruitful discussions and enhancement. Therefore, we really believe that this initiative strongly improve the learning process of the associated Microwave and Antenna Engineering courses, and it is extensible to any other Engineering course. The main condition is to find a practical and interesting application (in this case Radio Astronomy), making the students face an appealing Engineering task to develop their highest potential. A second but also indispensable condition is that Government (in the case of public Universities) and Faculty/University principals/managers give more value to any educative initiative that shows improvement in the quality of the learning process. This claim has not generally occurred in Spanish universities (and probably in many other well developed countries), where most of the value has been given value to lecturers' research results. Nowadays, this situation is changing (very slowly still).

\section{CONCLUSIONS AND FUTURE LINES}

Objectives 1-5 proposed in Section II of this paper have been reached so far. Particularly, a home-made SRT was developed by our students, being this activity very useful to develop practical, interdisciplinary, teamwork competences which have helped to a better acquisition of technical competencies and knowledge in the area of Microwave and Antenna Engineering (as demonstrated in Section IV).

Objectives 6-10 of Section II will only be achieved after the complete SRT laboratory is finished, so it can be remotely used between University students and for dissemination between high-school students and astronomy amateurs in the future. Particularly, objective 6 is a consequence of the success of the development of the SRT initial system and the good response of the students, so that this SRT will be used by the students to upgrade its performance and propose new applications. One of these future upgrades might be the design of an interferometer radio telescope (sketched in Fig.13), or the development of receivers and antennas working at other frequencies to detect other interesting signals from our Solar System and Universe. Moreover, the SRT is intended to participate in the SETI project [34,36], which can be another attractive application to increase the interest among the young students and future graduates. 


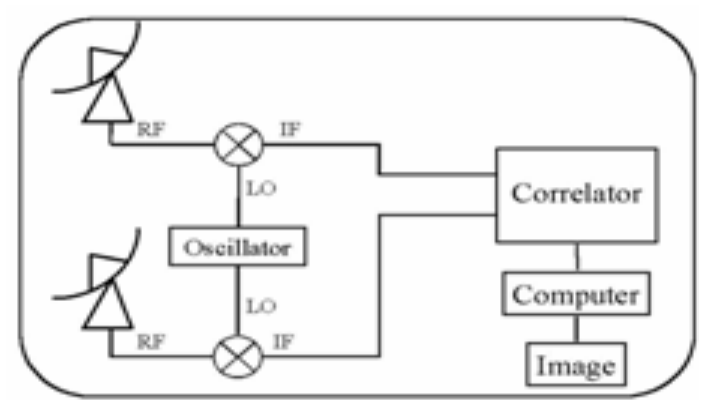

Figure 13. Scheme of a basic linked radio interferometer [11].

Nevertheless, the authors of this work believe that these types of initiatives are not given enough importance by the actual Academic system, which mainly score the lectures by their research results. This fact makes that the endeavor of University lecturers is set on pure research, not feeling worthy to waste time and energies carrying out dissemination projects like this one which might not be valued in accordance to the effort needed. However, the authors of this paper believe that these enterprises are of vital importance for Science and University's future, and moreover they are a duty with our students and society (moreover in the case of public Universities).

\section{ACKNOWLEDGMENT}

This work has been partially supported by Regional Séneca Foundation under project 02972/PI/05 during 20062008 [49], and partially by Technical University of Cartagena (UPCT) during 2009 and 2010. A version of this paper was presented in the IEEE EDUCON 2010 conference [50] and selected for submission to this journal. It received a commendation in the Knowledge and Competencies in Engineering area of this conference.

This project would have not been possible without the excellent response and enthusiasm of our students, which are named in chronological order (indicating the course years and the subsystem in which they worked as part of this project): Ricardo Alarcón Llamas (design of LNAs, 2005-2006), Pedro Enrique Ros Avilés (mixer, 20052006), Joaquín López Castaño (RF filters, 2005-2006), Mónica Martínez Mendoza (RF filters, 2005-2006), Anna Kamasheva (LNAs, 2006-2007), Gonzalo Peñafiel Beltrán (LNAs, 2006-2007), Mónica Moragón Serano (oscillator, 2006-2007), Adrián Juan Heredia (horn, 2006-2007), Francisco Javier Sandoval Piqueras (mixer, 2006-2007), Ramón Angosto Sánchez (parabolic dish, 2006-2007), Juan Antonio Rosell Franco (RF filters, 2007-2008), Javier Molero Madrid (down converter, 2007-2008), Jesús Mora Rodríguez (parabolic dish and down converter, 2008-2009), Marta Rodríguez García (parabolic dish and down converter, 2008-2009), Cynthia Cerezo (microwave detectors, 2008-2009), Miguel Damián Truque (parabolic dish and positioning system, 2009-2010), Pedro Bermejo (oscillators, 2009-2010), Javier Jimenez (positioning system and final down converter demonstrator board, 20092010), Antonio Jesús Muñoz Lapaz (multimedia webbased applications), María Isabel Ferrer (multimedia webbased applications), Ricardo Mármol (SRT web page, 2009-2010) and Samuel Góngora (remote control, 20092010). The authors want to acknowledge the support of Dr. Isidro Villó, Dr. Isidro Ibarra and Dr. Rafael Vilar from the UPCT, who made possible the final set-up of the parabolic dish and motors in the buildings of the UPCT, and also the scientific and technical wise advices of Dr. Isidro Villó (UPCT), Dr. José Carlos Guirado Puerta (University of Valencia, Spain), and Dr. José Ignacio González Serrano (University of Cantabria, Spain).

\section{REFERENCES}

[1] http://www.bologna-bergen2005.no/

[2] FECYT: http://www.fecyt.es

[3] R.E. Collin., Field Theory of Guided Waves, IEEE Press, 2nd Ed., John Wiley and Sons, 1990. doi:10.1109/9780470544648

[4] S. Ramo, J.R. Whinnery, T. van Duzer, Fields and Waves in Communication Electronics, 3rd Edition, John Wiley \& Sons, 1994.

[5] R.C. Johnson, Antenna Engineering Handbook, $3^{\text {rd }}$ Ed., Ed. New York, McGraw-Hill, 1993.

[6] C.A. Balanis, Antenna Theory, Analysis and Design, $2^{\text {nd }}$ Ed., John Wiley \& Sons, Inc., 1996.

[7] D.M.Pozar, Microwave Engineering, 3rdEd., JohnWiley and Sons, 1998.

[8] R.E. Collin, Foundations for Microwave Engineering, 2nd Ed., IEEE Press, 2001. doi:10.1109/9780470544662

[9] I. Bahl, Microwave Solid State Design, 2nd Ed,JohnWileyandSons, 2003.

[10] David M. Pozar, Microwave and RF wireless systems, John Wiley \& Sons 2000

[11] J.D. Kraus, Radio Astronomy, McGraw-Hill Education, 1966.

[12] B.F. Burke, Francis Graham-Smith, An Introduction to Radio Astronomy, 1994.

[13] D. Fisher, Basics of Radio Astronomy, Jet Propulsion Laboratory, 1997, Document No. JPL D-13835.

[14] G.L. Verschuur, The Invisible Universe: The Story of Radio Astronomy,2nd Ed, Springer; 2006

[15] J.M. Lichtman, Amateur Radio Astronomy, Systems, Procedures and Projects, 1993.

[16] Heiserman, Radio Astronomy for the Amateur, ISBN 0-83065714-2., TAB Books Co., 13311 Monterey Lane, Blue Ridge Summit Pa., 1993.

[17] W. Lonc, Radio Astronomy Projects, ISBN 1889076007, RadioSky Publishing, 1996.

[18] J.E. Salah, P. Pratap, A.E-E. Rogers, "The Educational Role of Small Telescopes in Radio Astronomy" in The Future of Small Telescopes In The New Millennium. Volume II - The Telescopes We Use. Terry D. Oswalt, ed.; Astrophysics and Space Science Library, Volume 288, Dordrecht: Kluwer Academic Publishers, p.323-336, 2003.

[19] County of Murcia Astronomers Agrupation: http://www.observa murcia.com/

[20] County of Cartagena Astronomers Association: http://usuarios. lycos.es/astronomia_cartagena/

[21] Radio Astronomy Supplies (RAS) http://www.radioastronomy supplies.com/

[22] Valencia University SRT http://www.uv.es/radioastronomia/

[23] Cantabria University STT http://www.ifca.unican.es/ gserrano/S $\underline{\mathrm{RT} /}$

[24] Down East Microwave Inc. (DEMI) http://www.downeastmicro wave.com/

[25] CASSICORP http://www.cassicorp.com/index.html

[26] RF Ham Design http://www.rfhamdesign.com/

[27] PARTnER project: http://laeff.inta.es/partner/

[28] O. Suarez, C. Blasco, J.F. Gomez, M. Herranz, B. Montesinos and J. García, "PARTNeR, a Radio Astronomy Experience for Students", Teachning and Communicating Astronomy, JENAM'04, EAS Publication Series, 16, 159-165, 2005.

[29] IAC, Astrophysics Institute of Canary Islands www.iac.es/

[30] IAA, Astrophysics Institute of Andalucia www.iaa.es/

[31] MIT Haystack Observatory SRT: http://www.haystack.mit.edu/ edu/undergrad/srt/index.html

[32] Cardiff University SRT: http://www.astro.cf.ac.uk/observatory/ radiotelescope/ 
[33] Saint Mary's University: http://www.ap.stmarys.ca/ lonc/radiotel. $\underline{\mathrm{html}}$

[34] SETI League http://seti1.setileague.org/

[35] SETI @ home: http://seti1.setileague.org/general/setihome.htm

[36] SETI Argus project: http://setil.setileague.org/argus/index.html

[37] SETI Argus SRT: http://seti1.setileague.org/hardware/blkdiag.htm

[38] Orbitron: http://www.stoff.pl/

[39] J.L.Gómez Tornero, Transmisión por Soporte Físico; Ejercicios resueltos de circuitos pasivos y activos de microondas, MORPI, S.L., 2006 (ISBN: 84-95781-70-0).

[40] Ansoft High-Frequency Structure Simulator (HFSS V.9 0), 2000: www.Ansoft.com

[41] Agilent Advance Design System ADS 2002, Momentum: http://eesof.tm.agilent.com/products/ads2002.html

[42] Applied Wave Research, Microwave Office (MWO), AWR 2002: http://web.appwave.com/Products/Microwave_Office/Overview.p hp

[43] Applied Wave Research,Visual System Simulator (VSS):

[44] http://web.appwave.com/Products/Visual_System_Simulator/

[45] Orcad PSPICE v9.1:

[46] http://www.cadence.com/products/orcad/index.aspx

[47] J.L. Gómez-Tornero, M. Moragón-Serrano, D. Cañete-Rebenaque, F.D. Quesada-Pereira, A. Álvarez-Melcón, Chapter 13, TICAI2007: TICs para el Aprendizaje de la Ingeniería, "Oscilador de microondas por generación de armónicos para facilitar el aprendizaje de circuitos de alta frecuencia", OIEEE, Sociedad de Educación: Capítulos Español, Portugués y Colombiano, Martín Llamas Nistal, Carlos Vaz de Carvalho, y Carlos Rueda Artunduaga, editores, ISBN 978-84-8158-380-9, pp.87-94, 2008 (in Spanish).

[48] UPCT SRT web page: http://www.upct.es/geat

[49] I+D+i builing at UPCT: http://www.upct.es/idi.htm

[50] MCSI, web based applications: http://www.wearewild.net/MCSI

[51] J.L Gómez-Tornero. Final Report, "Development of a Small Radio Telescope for Dissemination of Radio Astronomy and Microwave -Antenna Technologies, and Amateur Exploration of our Galaxy", project granted during years $2006-2008$ by Regional Seneca Foundation with code 02972/PI/05., Techn. University of Cartagena, Final Report, April 2009 (in Spanish).

[52] J.L. Gómez-Tornero, D. Cañete-Rebenaque, F.D. QuesadaPereira, A. Álvarez-Melcón, "Development of a Small Radiotelescope at the Technical University of Cartagena," IEEE Education Engineering 2010, EDUCON 2010, pp.1195-1201, April 2010.

\section{AUTHORS}

José Luis Gómez-Tornero is with the Technical University of Cartagena, in the Department of Information Technologies and Communications, Campus Muralla del
Mar, 30202 Cartagena, Spain (e-mail: josel.gomez@ upct.es). José Luis is Associate Professor at the Telecommunication Engineering Faculty, teaching in the area of Microwave and Antenna Engineering. In 2001, he joined the Technical University of Cartagena (UPCT), Spain, as an Assistant Professor. From October 2005 to February 2009, he held de position of Vice Dean for Students and Lectures affairs in the Telecommunication Engineering Faculty at the UPCT. Since 2008, he has been an Associate Professor at the Department of Communication and Information Technologies, UPCT. In 2001, José Luis started the SRT UPCT initiative, and since then he has coordinated and supervised this project.

David Cañete-Rebenaque is with the Technical University of Cartagena, in the Department of Information Technologies and Communications, Campus Muralla del Mar, 30202 Cartagena, Spain (e-mail: david.canete@) upct.es). David is Assistant Professor at the Telecommunication Engineering Faculty, teaching in the area of Optics for Engineering.

Fernando Daniel Quesada-Pereira is with the Technical University of Cartagena, in the Department of Information Technologies and Communications, Campus Muralla del Mar, 30202 Cartagena, Spain (e-mail: fernando.quesada@upct.es). Fernando is Associate Professor at the Telecommunication Engineering Faculty, teaching in the area of Electromagnetism and Antenna Engineering.

Alejandro Álvarez-Melcón is with the Technical University of Cartagena, in the Department of Information Technologies and Communications, Campus Muralla del Mar, 30202 Cartagena, Spain (e-mail: alejandro.alvarez@) upct.es). Alejandro is full-professor at the Telecommunication Engineering Faculty, teaching in the area of Electromagnetism and Antenna Engineering.

This work has been partially supported by Regional Séneca Foundation under project $02972 / \mathrm{PI} / 05$ during 2006-2008 [49], and partially by the Technical University of Cartagena (UPCT) during 2009 and 2010. A version of this paper was presented in the IEEE EDUCON 2010 conference [50] and selected for submission to this journal. It received a commendation in the Knowledge and Competencies in Engineering area of this conference.

This article was modified from a presentation at the EDUCON2010 Conference at Madrid, Spain in April 2010. Submitted, September, 30, 2010. Published as resubmitted by the authors on January $20^{\text {th }}, 2011$. 